\title{
Outcome of patients with systemic rheumatic disease admitted to medical intensive care units
}

Bertrand Godeau, Azzedine Boudjadja, Jean-François Dhainaut, Benoît Schlemmer, Claude Chastang, Fabrice Brunet, Jean-Roger Le Gall

Abstract

The outcome of patients admitted to intensive care units is known to be influenced by such factors as age, previous health status, severity of disease, and diagnosis. To estimate the outcome of such patients with systemic rheumatic diseases and to determine if the severity of these diseases unfavourably influences the prognosis at the time of admission to a medical intensive care unit, the clinical courses of all patients with systemic rheumatic disease admitted to two medical intensive care units between January 1978 and December 1988 were studied retrospectively.

Sixty nine patients with systemic lupus erythematosus $(n=16)$, necrotising vasculitis $(n=19)$, rheumatoid arthritis $(n=19)$, and other systemic rheumatic diseases $(n=15)$ were included. The mean (SD) age on admision into the medical intensive care unit was $\mathbf{5 3}$ (17) years and the mean simplified acute physiological score was $12(5.5)$. The principal diagnoses on admission were infectious complications (29/69 patients) and acute exacerbation of the systemic rheumatic disease (19/69 patients). The death rate in the medical intensive care unit was 33\% (23/69 patients) and was similar to that of a non-selected population with comparable simplified acute physiological score. The death rate in hospital was 42\% (29/69 patients). Infection was the main cause of death in the medical intensive care unit (19/23 patients) and the infection was mainly acquired in the unit. Only the simplified acute physiological score on admission was a statistically significant prognostic factor: the simplified acute physiological score in patients who died was 15 (5.2) $v$ 9.9 (4.7) for survivors. Long term outcome analysis showed that $83 \%(33 / 40$ patients) of patients were still alive after admission to the medical intensive care unit with a follow up time between two months and nine years (mean 38 months).

The death rate was relatively high and was mainly due to nosocomial infections. It was not different, however, from that of nonselected patients and the long term prognosis was highly favourable. This shows that the complications are often reversible, particularly infectious complications, and justifies admission to the medical intensive care unit of this group of patients.

The term 'systemic rheumatic disease' groups together acute and chronic diffuse inflammatory diseases which often need treatment with immunosuppressive drugs. ${ }^{1}$ The complications, prognoses, and causes of death of most of these diseases are known ${ }^{2-4}$ but the means of predicting the outcome of these patients at the time of their admission into medical intensive care units have never been studied. Age and the simplified acute physiological score are two major prognostic factors in the medical intensive care unit, but the previous health status and severity of disease also have an influence on prognosis. ${ }^{5} \mathrm{~A}$ bicentric retrospective study of 69 patients with systemic rheumatic disease admitted over an 11 year period was carried out to determine if the severity of the systemic rheumatic disease at the time of admission to the medical intensive care unit unfavourably influences the outcome of the patient.

\section{Patients and methods}

The study was carried out in the medical intensive care units of the Cochin Port-Royal and Saint Louis University Hospitals in Paris. The discharge summaries of all the patients admitted to these medical intensive care units were reviewed. All the patients with systemic rheumatic disease admitted between 1 January 1978 and 1 January 1989 were included. The diagnostic criteria for the main systemic rheumatic diseases were as follows: the diagnostic criteria for systemic lupus erythematosus, rheumatoid arthritis and systemic sclerosis were those of the American Rheumatism Association $^{6-8}$; for polymyositis and dermatomyositis those proposed by Bohan and Peter ${ }^{9}{ }^{10}$; and for necrotising vasculitis those defined by Fauci. ${ }^{11}$

ADMISSION TO THE MEDICAL INTENSIVE CARE UNIT Age, sex, type and duration of underlying systemic rheumatic disease, length of stay in hospital before admission to the medical intensive care unit, treatment with costicosteroids or cytotoxic drugs, and the simplified acute physiological score ${ }^{12}$ were recorded for each patient. Special attention was given to the major clinical reason for admission to the medical intensive care unit and these were classified as follows: (a) hypotension or shock, or both, defined by a systolic blood pressure of less than $90 \mathrm{mmHg}$, or use of vasopressors to maintain arterial blood pressure above this level; $(b)$ acute respiratory failure defined as a deterioration in gas exchange and the need for an increase in inspired oxygen concentration or mechanical ventilation, or both; (c) acute renal failure defined as a rapid deterioration in renal function sufficient to result in accumulation of nitro- 
genous wastes in the body ${ }^{13}$; and $(d)$ alterations in nervous system function including seizures, motor paralysis, coma, or alterations in mental status.

\section{EVENTS AND TREATMENT DURING STAY IN} MEDICAL INTENSIVE CARE UNIT

The following information was also collected: duration of stay in the medical intensive care unit, the need for mechanical ventilation, and the duration of mechanical ventilation.

\section{SHORT TERM OUTCOME}

Subjects were classified into one of three classes as follows: died in the medical intensive care unit, died in hospital, or discharged from the hospital (survivors). For patients who died in the medical intensive care unit, the probable cause of death and necropsy report were studied.

\section{LONG TERM OUTCOME}

Patients or their doctor were contacted by telephone after discharge.

\section{CONTROL GROUP}

All the patients admitted to hospital in the two medical intensive care units for diseases other than systemic rheumatic disease between 1 January 1985 and 1 January 1989 were included in a control group. The patients admitted to hospital before this period were not included in the control group because data on age, simplified acute physiological score, and death rate in the medical intensive care unit were not available for all patients. The control group included 2852 patients; their mean age was $53 \cdot 1$ years and their mean simplified acute physiological score on admission was 11.9 . The death rate in the medical intensive care unit was $25 \%$ (713/ 2852 patients).

\section{STATISTICAL ANALYSIS}

For multiple admissions, only the first admission to the medical intensive care unit was included (nine patients). The analysis used SAS software. Survival analysis was based on the KaplanMeier ${ }^{14}$ estimate and the log rank test. ${ }^{15}$ The findings at the reference date of 1 January 1989 were used.

\section{Results}

Table 1 gives the characteristics of the 69 patients with systemic rheumatic disease admitted to the two medical intensive care units during the study period. Eight patients were diagnosed for the first time as having systemic rheumatic disease while in the medical intensive care unit. Forty four of the 69 patients were being treated with corticosteroids for more than one month before admission to the medical intensive care unit; in 14 patients, the prednisone dose was lower than $10 \mathrm{mg} /$ day. Cytotoxic drugs were given in addition to corticosteroids in seven patients (cyclophosphamide(five patients), methotrexate (two patients).

Table 2 gives the major clinical problems prompting admission to the medical intensive care unit and the various diagnoses on admission. Infection was the most common reason for admission (29/69 patients).

Acute exacerbation of the systemic rheumatic disease led to the admission of 19 patients. These were mainly patients with systemic lupus erythematosus (6/19) and necrotising vasculitis (7/19 patients). Non-septic iatrogenic complications were the third most common diagnosis on admission (12/69 patients) and included

Table 1 Patient characteristics

\begin{tabular}{|c|c|c|c|c|c|c|c|}
\hline & $\begin{array}{l}R A \\
(n=19)\end{array}$ & $\begin{array}{l}S L E \\
(n=16)\end{array}$ & $\begin{array}{l}N V \\
(n=19)\end{array}$ & $\begin{array}{l}S S \\
(n=5)\end{array}$ & $\begin{array}{l}P M / D M \\
(n=6)\end{array}$ & $\begin{array}{l}\text { Misc } \\
(n=4)\end{array}$ & $\begin{array}{l}\text { Total } \\
(n=69)\end{array}$ \\
\hline $\begin{array}{l}\text { Sex ratio }(\mathrm{F} / \mathrm{M}) \\
\text { Mean (SD) age at admission (years) } \\
\text { Mean (SD) duration of systemic rheumat }\end{array}$ & $\begin{array}{l}14 / 5 \\
59(14)\end{array}$ & $\begin{array}{l}11 / 5 \\
41(17)\end{array}$ & $\begin{array}{l}5 / 14 \\
57(16)\end{array}$ & $\begin{array}{l}4 / 1 \\
54(8)\end{array}$ & $\begin{array}{l}5 / 1 \\
51(18)\end{array}$ & $\begin{array}{l}2 / 2 \\
60(16)\end{array}$ & $\begin{array}{l}41 / 28 \\
53(17)\end{array}$ \\
\hline $\begin{array}{l}\text { disease (months) } \\
\text { Mean (SD) length of preliminary }\end{array}$ & $196(107)$ & $50(74)$ & $27(30)$ & $86(88)$ & $15(19)$ & $52(51)$ & $84(101)$ \\
\hline $\begin{array}{l}\text { stay in hospital (days) } \\
\text { Mean simplified acute physiological }\end{array}$ & $13(21)$ & $18(29)$ & $27(41)$ & $2(2)$ & $18(35)$ & $34(42)$ & $19(31)$ \\
\hline $\begin{array}{l}\text { score on admission } \\
\text { Mean (SD) duration of stay in }\end{array}$ & $12 \cdot 4(5 \cdot 5)$ & $11 \cdot 9(5 \cdot 2)$ & $13 \cdot 3(5 \cdot 3)$ & $11 \cdot 6(3 \cdot 1)$ & $9(6 \cdot 2)$ & $9 \cdot 7(9)$ & $12(5 \cdot 5)$ \\
\hline medical intensive care unit (days) & $12(11)$ & $21(26)$ & $16(24)$ & $7(7)$ & $20(22)$ & $15(16)$ & $16(20)$ \\
\hline
\end{tabular}

(RA) Rheumatoid arthritis: (SLE) systemic lupus erythematosus; (NV) necrotising vasculitis; (SS) systemic sclerosis; (PM/DM) polymyositis and dermatomyositis; (misc) miscellaneous.

Table 2 Diagnosis on admission

\begin{tabular}{|c|c|c|c|c|c|c|}
\hline & $\begin{array}{l}\text { Acute } \\
\text { exacerbation } \\
\text { of } S R D \\
(n=19)\end{array}$ & $\begin{array}{l}\text { Infectious } \\
\text { complication } \\
(n=29)\end{array}$ & $\begin{array}{l}\begin{array}{l}\text { Iatrogenic } \\
\text { complication }\end{array} \\
(n=12)\end{array}$ & $\begin{array}{l}\text { Cardiovascular } \\
\text { complication } \\
(n=5)\end{array}$ & $\begin{array}{l}\text { Miscellaneous } \\
(n=4)\end{array}$ & $\begin{array}{l}\text { Total } \\
(n=69)\end{array}$ \\
\hline Mean (SD) age (years) & $46(20)$ & $56(18)$ & $57(7)$ & $56(10)$ & $52(16)$ & $53(17)$ \\
\hline \multicolumn{7}{|c|}{ Major clinical problem (No of patients) } \\
\hline Shock & 4 & 17 & 5 & 0 & $\mathbf{0}$ & 26 \\
\hline Acute renal failure & 3 & 0 & 2 & 1 & 1 & 7 \\
\hline $\begin{array}{l}\text { Respiratory failure } \\
\text { Alteration in nervous }\end{array}$ & 6 & 9 & 2 & 3 & 0 & 20 \\
\hline system function & 6 & 2 & 2 & 0 & 2 & 12 \\
\hline Miscellaneous & 0 & $\overline{1}$ & $\vec{l}$ & 1 & 1 & 4 \\
\hline $\begin{array}{l}\text { Mean (SD) simplified acute } \\
\text { physiological score on admission }\end{array}$ & $11 \cdot 4(5 \cdot 3)$ & $12 \cdot 6(5 \cdot 2)$ & $10.8(6.4)$ & $14 \cdot 2(7 \cdot 2)$ & $11 \cdot 8(4 \cdot 3)$ & $12(5 \cdot 5)$ \\
\hline
\end{tabular}


adverse drug effects in seven and complications due to an invasive diagnostic or therapeutic procedure in five patients. Five patients were admitted for cardiovascular complications which were not directly attributable to the systemic rheumatic disease. The remaining four patients were admitted for miscellaneous complications including one intracerebral haemorrhage, one seizure, one hepatic encephalopathy, and one multifactorial acute renal failure.

The figure shows the short term outcome and causes of death. The death rate in the medical intensive care unit was 33\% (23/69 patients) and the in hospital death rate was $42 \%(29 / 69$ patients). Of the 69 patients in the study, 41 were included between 1 January 1985 and 1 January 1989 and could therefore be compared with the control group. Their mean age was 54 years and their simplified acute physiological score on admission was 12.9 . The death rate in the medical intensive care unit of these 41 patients was $34 \%$ (14/41 patients) and was not significantly different from that observed in the 2852 patients of the control group $(25 \%)$ followed at the same time. Similarly, the mean

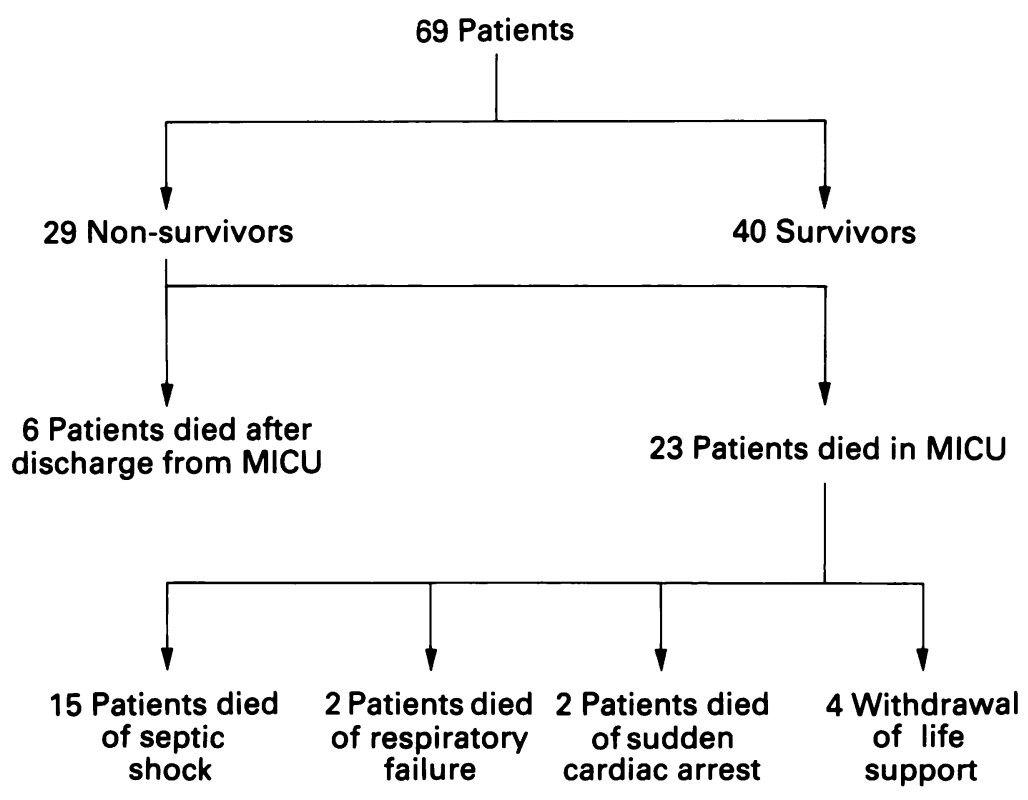

Short term outcome of patients admitted to the medical intensive care units (MICUS).

Table 3 Short term outcome of patients admitted to medical intensive care unit

\begin{tabular}{lcc}
\hline & $\begin{array}{c}\text { Non-survivors } \\
(\boldsymbol{n}=29)\end{array}$ & $\begin{array}{l}\text { Survizors } \\
(\boldsymbol{n}=40)\end{array}$ \\
\hline Mean age (years) & $56(14)$ & $51(18)$ \\
Systemic rheumatic diseases & & \\
(No of patients): & 3 & 13 \\
SLE & 9 & 10 \\
RA & 10 & 9 \\
NV & 4 & 1 \\
SS & 2 & 4 \\
PM/DM & 1 & 3 \\
Miscellaneous & $89(105)$ & $80(100)$ \\
Mean (SD) duration of systemic rheumatic disease (months) & \\
Diagnosis on admission & & 12 \\
(No of patients): & 7 & 14 \\
$\quad$ Exacerbation of SRD & 15 & 9 \\
Infectious complications & 3 & 3 \\
Iatrogenic complications & 2 & 2 \\
Cardiovascular complications & 2 & $9 \cdot 9(+\cdot 7)$ \\
Mean (SD) simplified acute physiological score on admission & $15(5 \cdot 2)$ & \\
(p<0.0006) & & \\
\hline
\end{tabular}

Abbreviations: (SLE) systemic lupus erythematosus; (RA) rheumatoid arthritis; (NV) necrotising vasculitis; (SS) systemic sclerosis; (PM/DM) polymyositis and dermatomyositis. ages and simplified acute physiological score on admission of the two groups were comparable.

Infection was the main cause of death in the medical intensive care unit. Eighty three per cent of patients (19/23) who died in the medical intensive care unit had septic complications, which were the sole cause of death for 12 patients. In the other seven patients, infection complicated an exacerbation of the systemic rheumatic disease. Infection manifested itself as septic shock (15 patients), acute respiratory distress syndrome due to pneumonia (two patients), and infectious meningitis (two patients). Microorganisms were isolated from 15 of the 19 patients who died of septic complications. Two patients had documented bacterial infections when admitted to the medical intensive care unit. All the other agents were isolated after admission to the medical intensive care unit and included seven Staphylococcus aureus, five Gram negative rods, and one Candida albicans with systemic manifestations. No viral, parasitic, nor mycobacterial infection was isolated. Only two deaths were solely attributable to an exacerbation of the systemic rheumatic disease and two deaths were caused by iatrogenic complications.

Table 3 summarizes the characteristics of survivors compared with the non-survivors. The study of prognostic factors influencing the short term medical intensive care unit outcome using univariate analysis and logistic regression shows that simplified acute physiological scores was the only prognostic factor $(p=0 \cdot 0006)$. The death rate tended to increase with age and to be higher in patients admitted for infectious complications (15/29 patients; $52 \%$ ) than those admitted for exacerbation of the systemic rheumatic disease (7/19 patients; $37 \%)$ of iatrogenic complications (3/12 patients; $25 \%$ ). No statistically significant differences were found, however. Mechanical ventilation was required for 36 patients of whom 23 died. Prolonged ventilation was compatible with survival: four patients ventilated for 20 days or more $(20,25$, 64 , or 69 days) survived.

The analysis of long term outcome showed that $83 \%$ of patients discharged from hospital (33/40 patients) were still alive after a follow up time of between two months and nine years (mean 38 months). One patient was lost to follow up and six patients died. Three deaths were secondary to infectious complications one, 13 , and 22 months after discharge from the medical intensive care unit.

\section{Discussion}

Numerous acute complications have been described in the course of systemic rheumatic disease. These complications are more likely as the duration of the disease increases. Health related quality of life also diminishes with long term disease. Admission to a medical intensive care unit may be questionnable when the short term prognosis is poor, especially in an era of increasing awareness of high health expenditure. In our study, however, the short term outcomes of the patients with systemic rheumatic disease admitted to the medical intensive care unit were 
similar to those of non-selected patients, and the long term prognosis was favourable.

Simplified acute physiological score was the only prognostic factor that was significantly associated with death. The influence of the diagnosis on admission on short term prognosis is also worth noting; patients admitted for infectious complications tend to have a poorer outcome than the other groups (Table 3). This is not statistically significant, however, probably because of the small number of patients. The group of patients with infectious complications were otherwise indistinguishable from the other groups of patients (Table 2). Age was not a statistically significant prognostic factor, in contrast with previously reported results, ${ }^{5}$ but again is probably due to the small sample size.

The death rate in the medical intensive care unit was high at $33 \%$. The death rate in our series, however, was not significantly higher than the death rate of non-selected patients with comparable simplified acute physiological score followed at the same time in the same medical intensive care unit. We did not find a disease effect on the prognosis as previously described by several workers for other severe diseases such as acute haemorrhagic pancreatitis ${ }^{16}$ or haematological malignancy ${ }^{17}$ where the prognosis is extremely unfavourable even in patients with only one or two organ system failures. ${ }^{19}$

The death rate observed in the group of mechanically ventilated patients was high (63\%). This was not unexpected as mechanical ventilation is known to have large and unfavourable effects on prognosis. ${ }^{20}$ Unlike cancer or malignant haemopathy, however, ${ }^{17}$ prolonged ventilation is not incompatible with survival (four survivors were ventilated for more than 20 days). Most of the patients received treatment with immunosuppressive drugs, although none were neutropenic during their stay in the medical intensive care unit. This may be the reason for the relatively good tolerance to prolonged ventilation.

Infection was the main diagnosis on admission and the main cause of death. Accordingly, Hellman et al suggested that death often results from the interplay of multiple processes and that infection can be a major contributor to the patient's death. ${ }^{21}$ Staphylococcus aureus, Gram negative rods, and opportunistic bacteria are common nosocomial infections in immunocompromised adults. ${ }^{22} 23$ Indeed, in our series, bacteria were isolated from 15 patients who died in the medical intensive care unit. Thirteen had Staphylococcus aureus or Gram negative rods which were acquired during the stay in the medical intensive care unit. In contrast, only one patient died of an opportunistic infection (systemic candidosis). Opportunistic infections are often diagnosed at necropsy, however, ${ }^{21} 23$ and it seems possible that some opportunistic infections were not recognised.

In our study, the severity of nosocomial infectious complications is not surprising as most patients were receiving corticosteroids or cytotoxic drugs on admission to the medical intensive care unit. Moreover, it is now well established that infection is a common cause of morbidity and death in systemic rheumatic disease. A multicentric study analysing the causes of death in patients with systemic lupus erythematosus showed that $33 \%$ of deaths were secondary to sepsis. ${ }^{2}$ Hellmann et al found similar results and suggested that the frequency of these infectious complications may result from the use of cytotoxic drugs or corticosteroids, which were commonly used in the three months before infection, even in the absence of leukopenia. ${ }^{21}$ Similar findings have been reported for vasculitis, where Guillevin et al found that $26 \%$ of deaths were caused by infectious complications. $^{4}$

Gastrointestinal complications were rare. Only three patients were admitted for this class of complication. Other workers have reported different results ${ }^{42}$; gastrointestinal complications are common and are the main cause of death in patients with vasculitis. The difference is probably due to the admission policy of our medical intensive care unit where patients with surgical complications are rare.

A study of the long term outcome is essential to estimate the effect of admission to a medical intensive care unit for patients with chronic and irreversible disease. ${ }^{25}$ In these patients, death rates are often low in the hospital but high after discharge. This result was not found in our study. On the contrary, although the death rate in hospital is relatively high, prolonged subsequent survival was observed. This suggests that complications are potentially reversible and justifies admission to the medical intensive care unit, particularly for infectious complications.

From our data, it seems reasonable to admit patients with systemic rheumatic diseases to the medical intensive care unit in spite of the relatively high death rate from nosocomial infections. The short term prognosis is similar to that of a non-selected population. Above all, the favourable long term prognosis in these patients shows that full recovery is possible.

We are indebted to Professor Jean-Charles Piette and to Drs Bruno Schremmer and Pascal Borderies for their assistance in reviewing this paper.

1 Petersdorf R G, Adams R D, Braunwald E, Isselbacher K J, eds. Harrison's principles of internal medicine. 10th ed. International Student Edition. New York: McGraw-Hill, 1983.

2 Rosner S, Gintzler E M, Diamond H S, et al. A multicenter study of outcome in systemic lupus erythematosus. Arthritis Rheum 1982; 25: 612-7.

3 Mitchell D M, Spitz P W, Young D Y, et al. Survival, prognosis, and causes of death in rheumatoid arthritis. prognosis, and causes of death in
Arthritis Rheum 1986; 29: 706-14.

4 Guillevin L, Le Thi Huong Du Z, Godeau P, Jais P, Wechsler B. Clinical finding and prognosis of polyarteritis nodosa and Churg-Strauss angiitis: a study in 165 patients. $\mathrm{Br}$ J Rheumatol 1988; 27: 256-64.

5 The French Multicenter Group of ICU Research. The Inserm unit 169 of statistical and epidemiological studies: factors related to outcome in intensive care: French multicenter related to outcome in intensive care:
study. Crit Care Med 1989; 17: 305-8.

6 Tan E M, Cohen A S, Fries J F, et al. The 1982 revised criteria for the classification of systemic lupus erythematosus. Arthritis Rheum 1982; 25: 1271-7.

7 Arnett F C, Edworthy S M, Bloch D A, et al. The 1987 revised ARA criteria for rheumatoid arthritis (RA). Arthritis Rheum 1988; 31: 315-24.

8 Subcommittee for Scleroderma Criteria of the American Rheumatism Association Diagnostic and Therapeutic Criteria Committee. Preliminary criteria for the classification of systemic sclerosis (scleroderma). Arthritis Rheum 1980; 23: $581-90$.

9 Bohan A, Peter J B. Polymyositis and dermatomyositis. N Englf Med 1975; 292: 344-7.

10 Bohan A, Peter J B. Polymyositis and dermatomyositis. $N$ Engl f Med 1975; 292: 403-7. 
11 Fauci A S. Vasculitis. I Allergy Clin Immunol 1983; 72: 211-23.

12 Le Gall J R, Loirat P, Alperovitch A, et al. A simplified acute physiology score for ICU patients. Crit Care Med 1984; 12 : 975-7.

13 Anderson $R$ J, Schrier $R$ W. Acute renal failure. In: Petersdorf R'G, Adams R D, Braunwald E, Isselbacher $\mathrm{K} \mathrm{J}$, eds. Harrison's principles of internal medicine. 10th ed. International Student Education. New York: McGrawHill, 1983: 1606-12.

14 Kaplan E, Meier P. Non-parametric estimation from in complete observations. F Am Stat Assoc 1958; 53: 457-81.

15 Peto R, Peto J. Asymptotically efficient rank invariant test procedures (with discussion). Foumal of the Royal Statistical Society 1972; A135: 185-90.

16 Loirat P, Gayraud M, Rigattieri S. Comparison of three severity score indexes in acute hemorrhagic pancreatitis. Intensive Care Medicine 1983; 9: 236.

17 Schuster D P, Marion J M. Outcome in patients with hematologic malignancy. Am $\mathcal{f}$ Med 1983; 75: 402-8.

18 Brunet F, Lanore J J, Dhainaut J F, et al. Is intensive care justitied tor patients with haematological malignancies? Intensive Care Medicine 1990; 16: 291-7.

19 Knaus W A, Draper E A, Wagner D P, Zimmerman J E. Prognosis in acute organ-system failure. Ann Surg 1985; 202: 685-93

20 Strieter R M, Lynch J P. Complications in the ventilated patient. Clin Chest Med 1988; 9: 127-39.

21 Hellmann D, Petri M, Whiting-O'Keefe Q. Fatal infections in systemic lupus erythematosus: the role of opportunistic in systemic lupus erythematosus: the role of opport
organisms. Medicine (Baltimore) 1987; 66: 341-8.

22 Craven D E, Kunches L M, Lichtenberg D A, et al. Nosocomial infection and fatality in medical and surgical intensive care unit patients. Ann Intern Med 1988; 148: $1161-8$.

23 Young L S. Nosocomial infections in the immunocompromised adult. Am f Med 1981; 70: 398-404.

24 Zizic T M, Classen J N, Stevens M B. Acute abdominal complications of systemic lupus erythematosus and poly arteritis nodosa. Am $\mathcal{F}$ Med 1982; 73: 525-31.

25 Thibault G E, Mulley A G, Barnett G O, et al. Intensive care: indications, interventions, and outcomes. $N$ Engl $7 \mathrm{Med}$ 1980; 302: 938-42. 